\title{
Membangun Server Portable untuk VoIP dan Web Server di Linux Ubuntu
}

\author{
Build Portable Server for VoIP and Web Server in Linux Ubuntu
}

\author{
Dwiny Meidelfi, Hidra Amnur \& Afrima Deki
}

Jurusan Teknologi Informasi Politeknik Negeri Padang Kampus Limau Manis Padang

Telp.0751-72590 Fax.0751-72576 Email: dwinymeidelfi@pnp.ac.id

\begin{abstract}
Server is a computer that serves a particular task in the network which can be used by other computers. The server damage will cause some losses in various parties who use the server services. Losses can be in the form of financial or others. The server damage can also be caused by natural disasters, such as earthquakes, floods, landslides and others. Therefore, it is necessary to create a portable server for VoIP and web server. VoIP servers are built by using asterisk as well as using the zoiper app and 3CX Phone to run VoIP. Meanwhile, the web server is created by using sentora panel. sentora panel is used because it has an installed packet like apache, php, mysql, phpmyadmin and other supporting software, hence it does not need to install it one by one. This portable server can be taken anywhere and can also be used in various PC or Laptop. So when the natural disaster occurs, the server stay safe, and ready to use.
\end{abstract}

Keywords: Server portable, Voip, Web Server, Asterisk, Sentora Panel, zoiper, 3CX Phone

\section{PENDAHULUAN}

Perkembangan teknologi informasi dan komunikasi semakin hari semakin berkembang, perkembangan teknologi informasi ini mempengaruhi kebutuhan akan informasi yang semakin cepat tanpa dibatasi oleh waktu ataupun letak geografis. Kebutuhan informasi yang cepat dan dapat diakses oleh siapapun dapat mengakomodasi layanan suara atau Voice Over Internet Protocol (VoIP) dan data berupa web server. Hal ini dapat dilihat dengan semakin cepat informasi-informasi terbaru yang dapat diakses dan dilihat oleh siapapun hanya dengan menggunakan perangkat digital seperti komputer, notebook, telepon selular. Sementara itu, penggunaan teknologi informasi sudah cukup banyak terutama oleh kampus, perusahaan, pemerintahan, sekolah dan lain-lain.

Dibalik tersedianya layanan informasi yang dapat diakses dan dimanfaatkan oleh siapapun terdapat suatu perangkat utama yang memiliki peranan penting, yaitu Server. Server merupakan komputer yang melayani tugas tertentu dalam jaringan yang kemudian dapat digunakan oleh komputer lainnya. Kerusakan server akan berakibat kerugian bagi berbagai pihak yang ikut menggunakan layanan server tersebut. Kerugian bisa dalam bentuk financial ataupun kerugian lainnya. Kerusakan server juga bisa disebabkan oleh bencana alam, seperti gempa bumi, banjir tanah longsor dan lainnya.

Untuk itu perlu membuat server portable di USB flashdisk, server ini bisa dibawa kemana saja dan juga bisa digunakan di berbagai PC atau Laptop kapan saja. Sehingga di saat terjadi bencana alam server tetap bisa aman dan masih bisa digunakan. Untuk mengatasi permasalahan tersebut, perlu dibangun server portable untuk voip dan web server di linux ubuntu

\section{METODOLOGI}

Server dalam dunia komputer adalah sebuah sistem komputer yang menyediakan jenis layanan tertentu dalam sebuah jaringan komputer. Server didukung dengan prosesor yang bersifat scalable dan RAM yang besar, juga dilengkapi dengan sistem operasi khusus, yang disebut sebagai 
sistem operasi jaringan atau network operating system. Server juga menjalankan perangkat lunak administratif yang mengontrol akses terhadap jaringan dan sumber daya yang terdapat di dalamnya, seperti halnya berkas atau alat pencetak (printer), dan memberikan akses kepada workstation anggota jaringan. Umumnya, di atas sistem operasi server terdapat aplikasiaplikasi yang menggunakan arsitektur client/server. Contoh dari aplikasi ini adalah DHCP Server, Mail Server, HTTP Server, FTP Server, DNS Server dan lain sebagainya [1].

VoIP (Voice over Internet Protocol) adalah teknologi yang mampu mengirimkan trafik suara, video dan data yang berbentuk paket secara real-time dengan jaringan Internet Protocol. VoIP memanfaatkan infrastruktur internet yang sudah ada untuk berkomunikasi seperti layaknya menggunakan telepon biasa dan tidak dikenakan biaya telepon biasa untuk berkomunikasi dengan pengguna VoIP lainnya dimana saja dan kapan saja [2]. Teknik dasar Voice over Internet Protocol atau yang biasa dikenal dengan sebutan VoIP adalah teknologi yang memungkinkan kemampuan melakukan percakapan telepon dengan menggunakan jalur komunikasi data pada suatu jaringan (networking), sehingga teknologi ini memungkinkan komunikasi suara menggunakan jaringan berbasis IP (internet protocol) untuk dijalankan diatas infrastruktur jaringan packet network. Jaringan yang digunakan bisa berupa internet atau intranet. Teknologi ini bekerja dengan jalan mengubah suara menjadi format digital tertentu yang dapat dikirimkan melalui jaringan IP. Teknologi ini pada dasarnya mengkonversi sinyal analog (suara) ke format digital dan kemudian dikompres atau ditranslasikan ke dalam paket-paket IP yang kemudian ditransmisikan melalui jaringan internet. Standarisasi protocol komunikasi pada teknologi VoIP adalah SIP (Session Initiation Protocol) dan H.323 [2]. Bentuk voice over internet protocol dapat dilihat pada Gambar 1.

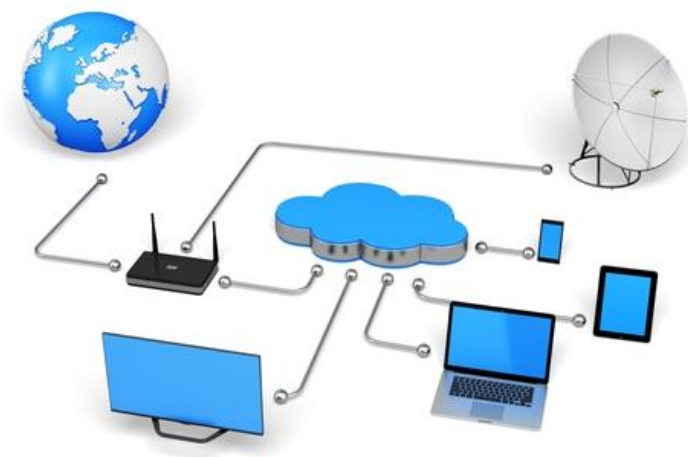

Gambar 1. Voice over Internet Protocol (VoIP)

Web server adalah sebuah sistem yang menyediakan tempat bagi halaman web agar dapat diakses oleh web client/browser. Karena menggunakan arsitektur client-server maka web kepada client. Web server dapat menerima permintaan HTTP dan kemudian meresponnya dengan mengirimkan kodekode HTML [3]. Secara umum, web server memiliki fungsi untuk menerima request dan merespon request dari client melalui browser pada jalur protokol komunikasi yang kemudian di teruskan kembali ke client berupa hasil yang ada berupa datadata seperti gambar, tulisan, video, atau dokumen. Sederhananya pengertian web server adalah sebuah perangkat lunak (peladen situs/server web) yang merespon permintaan dari client (menggunakan web browser) ke tempat data di letakan / disimpan, yang kemudian dikirimkan melalui jalur http (Hypertext Transmit Protocol)/ https (Hypertext Transmit Protocol Secure) dan di tampilkan di halaman web browser yang digunakan oleh client [7].

Database server adalah sebuah program komputer yang menyediakan layanan pengelolaan basis data dan melayani komputer atau program aplikasi basis data yang menggunakan model clientserver. Istilah ini juga merujuk kepada sebuah komputer (umumnya merupakan server) yang diperuntukkan untuk menjalankan program basis data. Sistem manajemen basis data (SMBD) pada umumnya menyediakan fungsi-fungsi basis 
data. Beberapa manfaat yang diberikan oleh database server antara lain adalah :
a. Meningkatkan pencarian dan pengambilan data.
b. Menambah tingkat keamanan data.
c. Database server didesain dan dioptimasi untuk melayani permintaan dari banyak user dan tidak terpengaruh dengan besarnya data yang telah ada [8].

Linux adalah sistem operasi turunan dari UNIX, yang merupakan implementasi dari standar IEEE untuk OS yang bernama POSIX (Portable Operating system interface). Linux mempunyai kemampuan yang berbasis standar POSIX meliputi multitasking, virtual memory, shared libraries, proper memory management, dan multiuser [9].

Ubuntu merupakan salah satu distro turunan Debian. Debian atau lengkapnya Debian GNU/Linux, GNU merupakan singkatan dari "GNU is Not Linux". Proyek GNU dimulai pada tahun 1984, bertujuan untuk menghasilkan sebuah sistem operasi miri Unix atau Unix-like yang bersifat free. Debian atau GNU/Linux adalah hasil dari proyek tersebut. Saat ini, Debian telah dikembangkan menjadi berbagai distro turunan, salah satunya bernama Ubuntu [4]. Asterisk adalah salah satu software opensource berbasis OS linux. Asterisk merupakan implementasi dari PBX (Private Branch Exchange) yang dibuat oleh mark spencer dari Gigium.Inc pada tahun 1999. Asterisk pada dasarnya adalah server voip, asterisk mencakup banyak fitur yang tersedia dalam sistem PBX seperti voice mail, panggilan konferensi, respon suara interaktif (menu telepon), dan distribusi panggilan otomatis. Pengguna dapat membuat fungsi baru dengan menulis script dial plan dalam beberapa bahasa ekstensi Asterisk sendiri [5].

Sentora adalah panel kontrol hosting opensource web yang dibangun khusus untuk mengerjakan berbagai distribusi Linux. Sentora dilisensikan di bawah GPLv3 dan merupakan garpu yang dipelihara secara terpisah dari proyek
ZPanel asli. Sentora dikembangkan dan dikelola oleh anggota asli tim Zpanel [6].

\section{HASIL DAN PEMBAHASAN}

Dalam sebuah PC terdapat sebuah server untuk Voice over Internet Protocol (VoIP) dan web server. VoIP digunakan untuk melakukan percakapan telepon dengan menggunakan jalur komunikasi data pada suatu jaringan (networking), sehingga teknologi ini memungkinkan komunikasi suara menggunakan jaringan berbasis IP (internet protocol) untuk dijalankan diatas infrastruktur jaringan packet network. Sedangkan web server digunakan untuk menyediakan tempat bagi halaman web agar dapat diakses oleh web client/browser. Topologi sistem yang ada saat ini dapat dilihat pada Gambar 2, sedangkan topologi yang dibuat dapat dilihat pada Gambar 3.

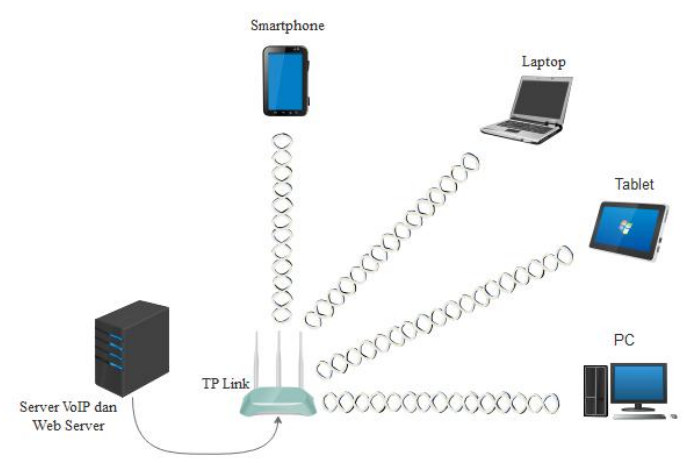

Gambar 2. Topologi sistem yang ada

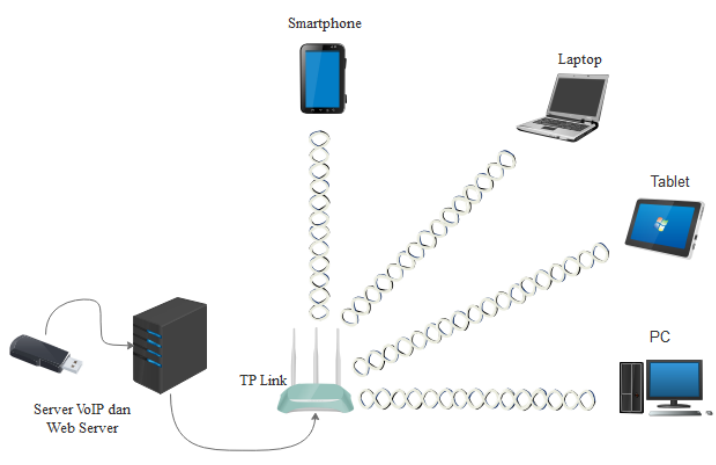

Gambar 3. Topologi sistem yang dibangun

Sebelum membangun server portable untuk VoIP dan web server menggunakan ubuntu maka dilakukan instalasi ISO ubuntu di USB flashdisk 
menggunakan aplikasi Universal USB Installer, instalasi dan konfigurasi asterisk, instalasi dan konfigurasi web server seperti apache, mysql, php, phpmyadmin, dan sentora sebagai CPanel serta instalasi dan konfigurasi aplikasi untuk mengakses VoIP. Langkah pertama yang dilakukan yaitu melakukan Installer ISO ubuntu diflashdisk menggunakan aplikasi Universal USB Installer. Adapun langkah-langkahnya adalah sebagai berikut:

a. Menghubungkan flashdisk ke-port USB pada PC atau laptop, setelah dibuka aplikasi Universal USB Installer. Maka akan tampil seperti Gambar 4.

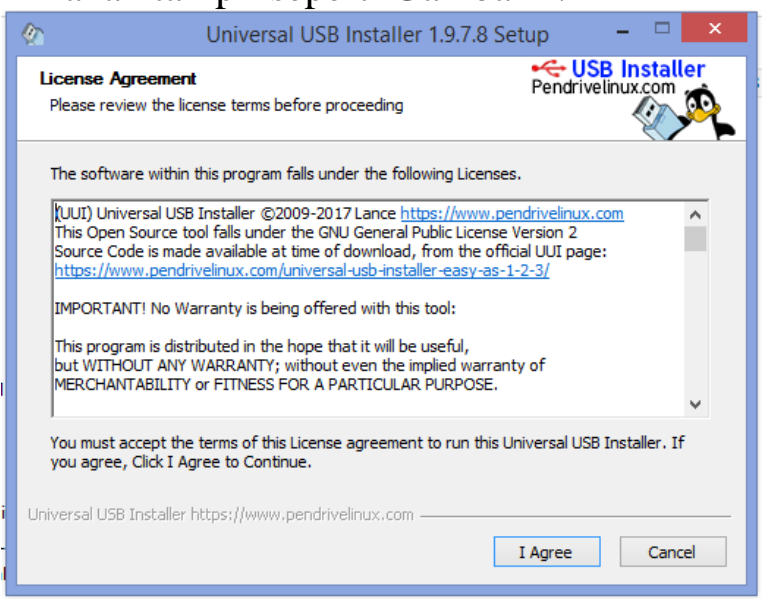

Gambar 4. License Agreement

b. Selanjutnya akan muncul jendela pilihan, seperti pada Gambar 5.

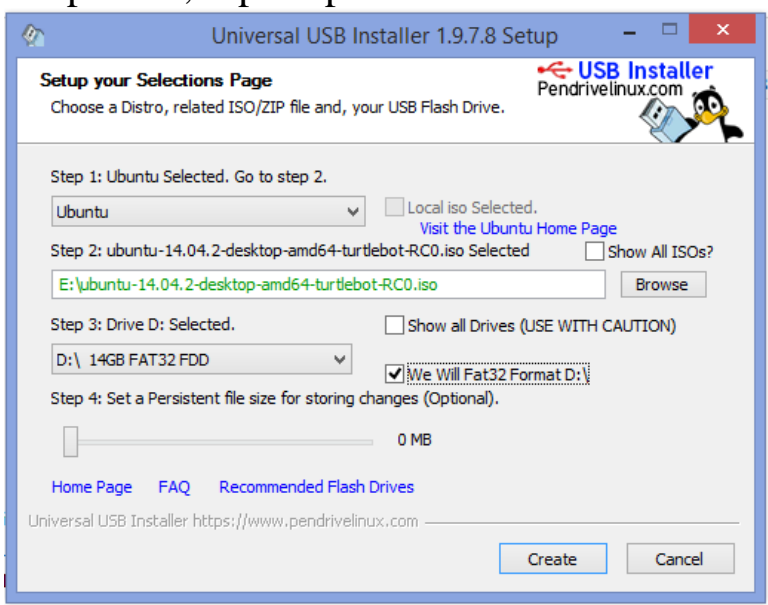

Gambar 5. Setup Selections Page

c. Kemudian konfirmasi untuk melakukan installer ISO ubuntu dan proses installer ISO ubuntu ke-flashdisk pun berjalan, seperti terlihat pada Gambar 6 .

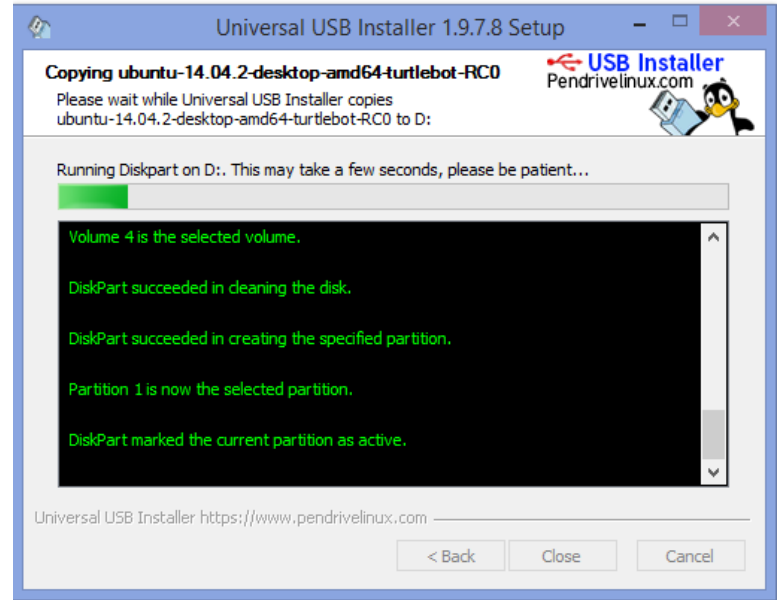

Gambar 6. Proses Meng-copy Data

Setelah melakukan Installer ISO ubuntu di-flashdisk, langkah selanjutnya adalah menginstal ubuntu di-flashdisk. Adapun langkah-langkahnya adalah sebagai berikut:

a. Flashdisk yang digunakan ada 2, Satu digunakan untuk menginstall ubuntu sedangkan yang satunya lagi untuk disk penyimpanan sistem operasi ubuntu disaat pembagian partisi

b. Disaat PC atau laptop dinyalakan maka akan tampil beranda seperti yang dapat terlihat pada Gambar 7.

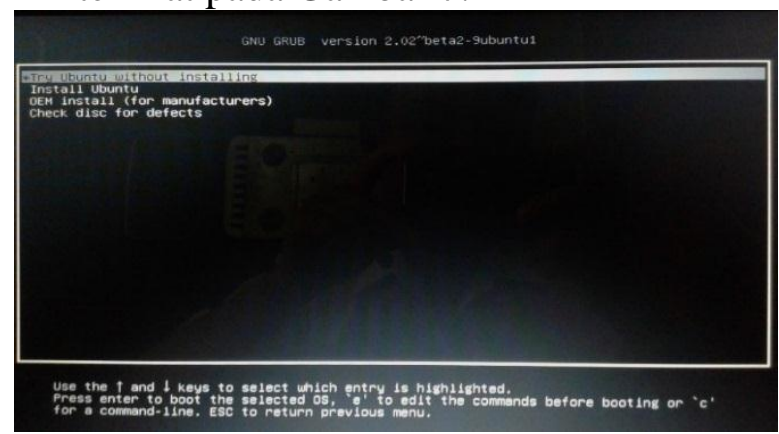

Gambar 7. Tampilan Beranda Awal

c. Setelah mememilih Try Ubuntu without Installing maka akan tampil seperti Gambar 8. 


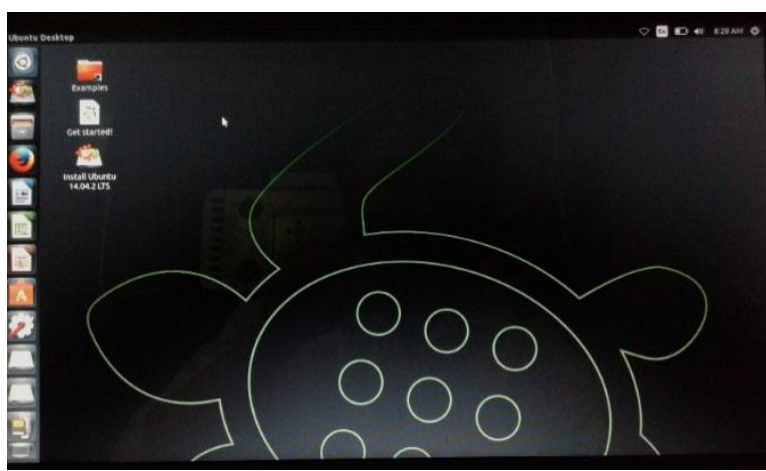

Gambar 8. Tampilan Ubuntu Sebelum Diinstal

d. Selanjutnya pada bagian ini merupakan pemilihan bahasa saat melakukan instalasi ubuntu dapat dilihat pada Gambar 9.

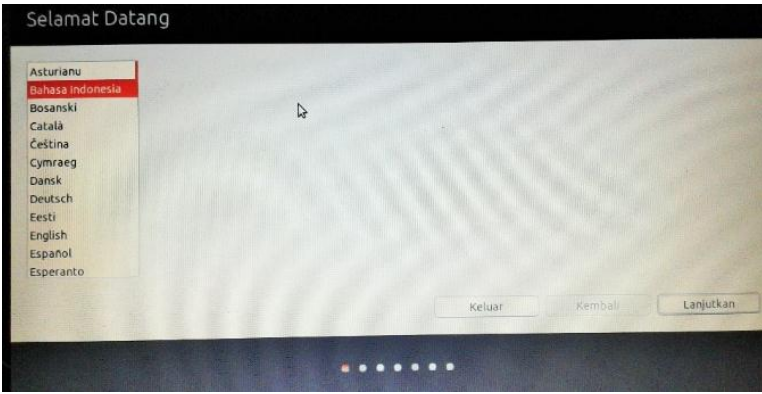

Gambar 9. Tampilan Pilihan Bahasa

e. Selanjutnya memilih "saya tidak mau menyambung ke jaringan wifi saat ini" karena pada saat menginstal ubuntu tidak terhubung dengan jaringan. Seperti yang terlihat pada Gambar 10.

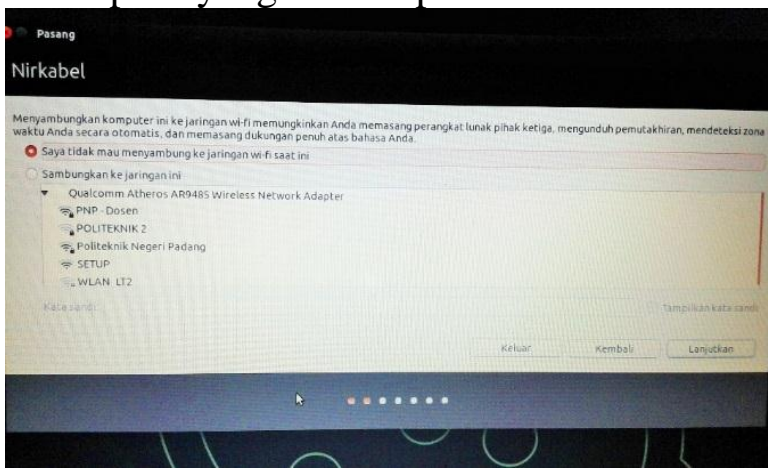

Gambar 10. Memilih Jaringan

f. Selanjutnya pemasangan ubuntu, pada tahapan ini di-ceklist pasang perangkat lunak pihak ketiga gunanya untuk mendownload paket-paket yang berhubungan dengan multimedia seperti mpeg, mp3 dan lain sebagainya, seperti yang terlihat pada Gambar 11.

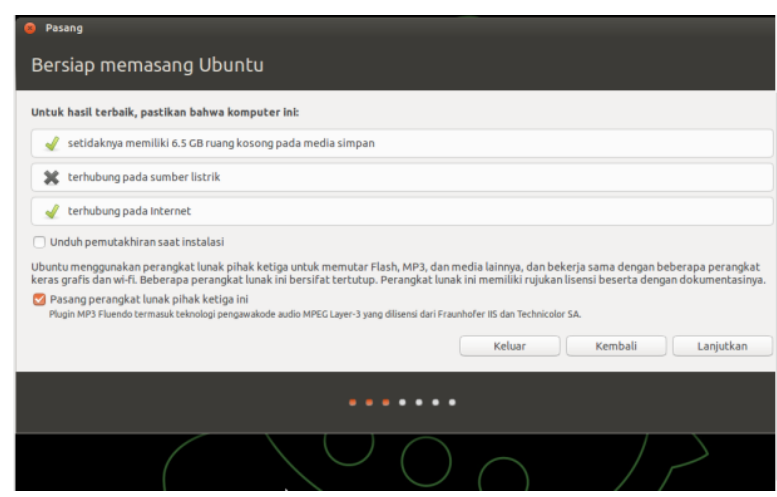

Gambar 11. Memasang Ubuntu

g. Sebelum membagi partisi dipilih sesuatu yang lain gunanya untuk partispasi jika ada terdapat data penting dalam partisi harddisk. Seperti yang terlihat pada Gambar 12.

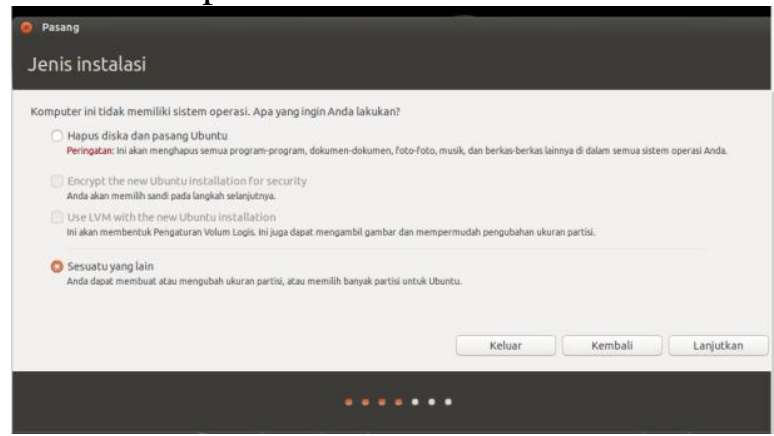

Gambar 12. Jenis Instalasi

h. Selanjutnya pembagian partisi, pada bagian partisi ini partisi yang dipilih yaitu /dev/sdb1 yang merupakan flashdisk yang akan digunakan. Kemudian dipilih change untuk membuat partisi pada flashdisk, setelah selesai mengatur semua diklik ok untuk proses selanjutnya. Seperti yang terlihat pada Gambar 13.

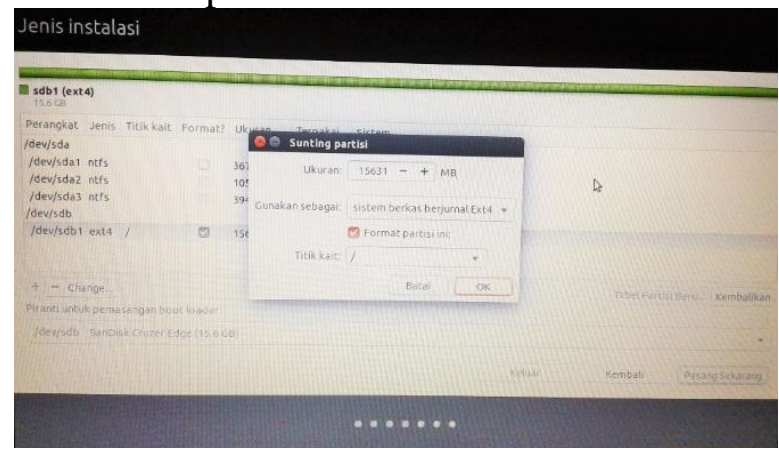

Gambar 13. Pembagian Partisi 
i. Selanjutnya memilih posisi wilayah, wilayah yang dipilih adalah jakarta. Seperti yang terlihat pada Gambar 14.

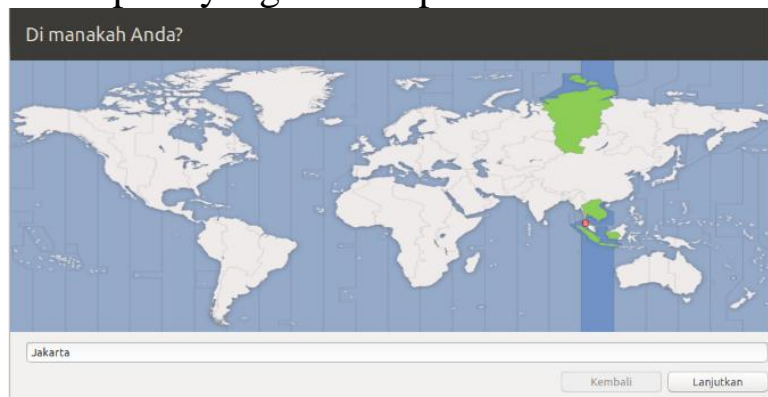

-.....

Gambar 14. Pengaturan Wilayah

j. Kemudian, pada bagian ini menggunakan susunan papan ketik (keyboard) Inggris (AS), seperti yang telihat pada Gambar 15.

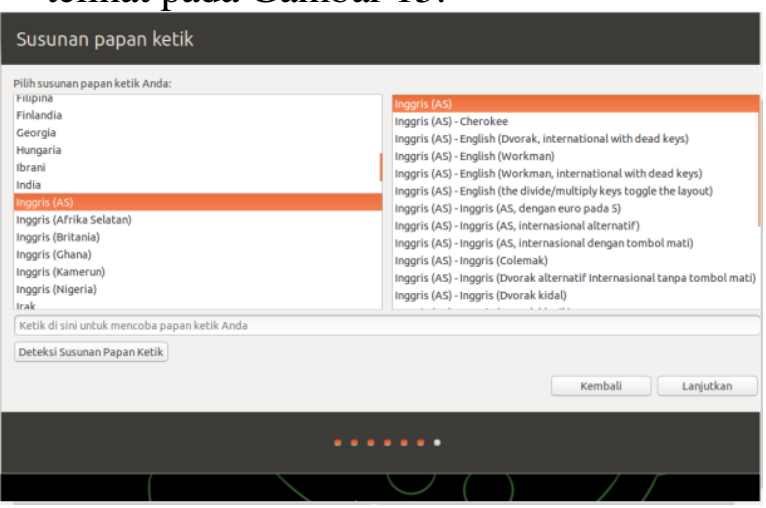

Gambar 15. Susunan Papan Ketik

k. Selanjutnya pembuatan nama dan password pada ubuntu. Nama dan password ini digunakan untuk masuk atau login ke ubuntu seperti yang terlihat pada Gambar 16.

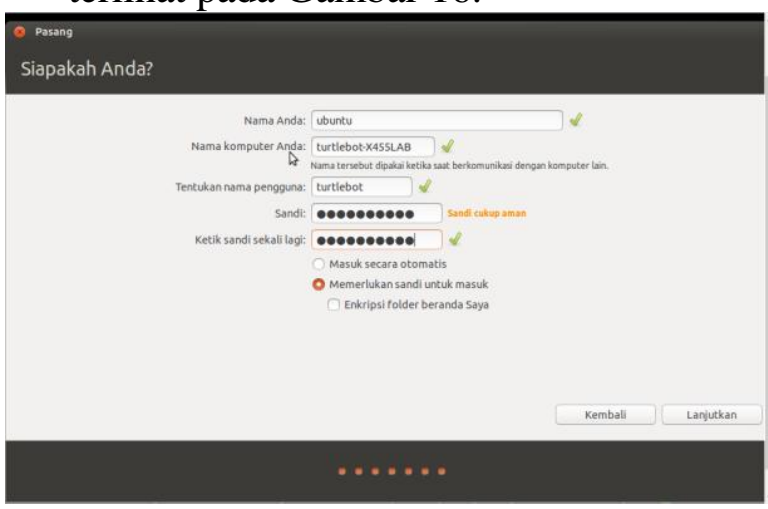

Gambar 16. Pembuatan Nama dan Password
1. Selanjutnya proses penginstalan ubuntu, seperti yang terlihat pada Gambar 17 .

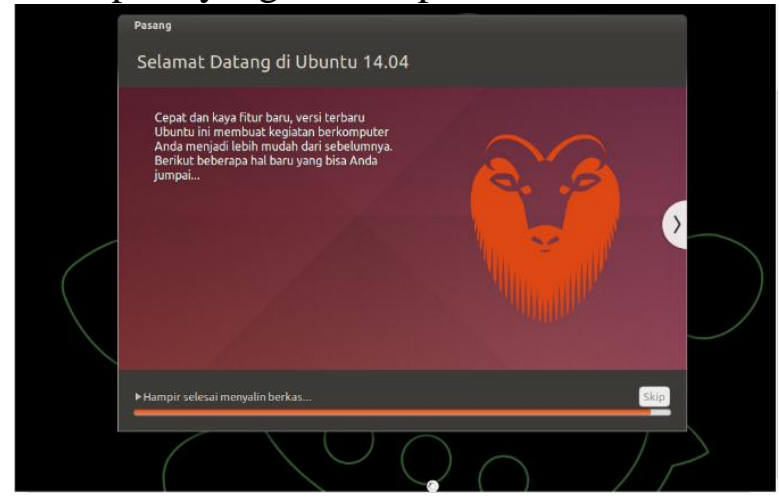

Gambar 17. Proses Instalasi Ubuntu

m. Setelah proses instalasi semua selesai, selanjutnya di-restart PC atau laptop, maka proses penginstalan ubuntu sudah selesai dan sudah bisa digunakan.

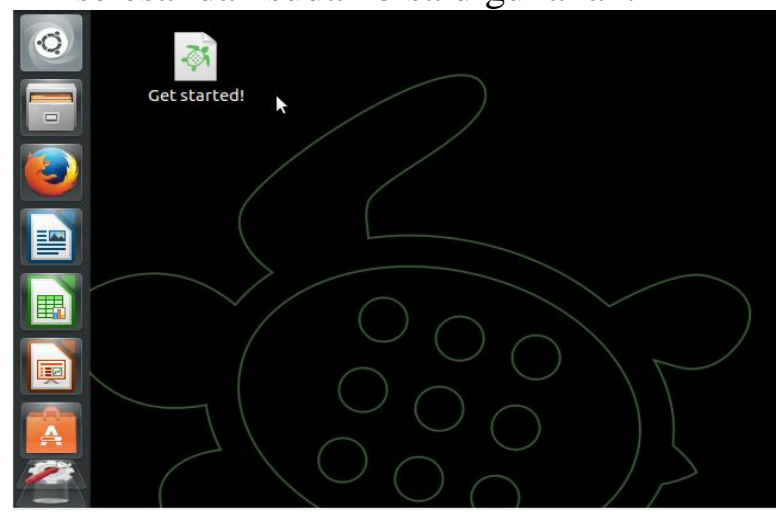

Gambar 18. Tampilan Ubuntu

Setelah proses instalasi Ubuntu selesai, selanjutnya melakukan instalasi Asterik untuk VOIP. Langkah-langkah instalasi Asterik sebagai berikut :

a. Membuka terminal ubuntu terlebih dahulu, setelah itu membuka root. Sebelum menginstal asterisk terlebih dahulu melakukan update, meng-update ini digunakan sebagai pembaharuan untuk memperbaiki masalah dengan memperbaharui sebuah program komputer atau menambah data pendukung, termasuk juga memperbaiki kelemahan-kelemahan (bug) dan memanfaatkan kegunaan atau kinerjanya. Seperti yang terlihat pada Gambar 19. 


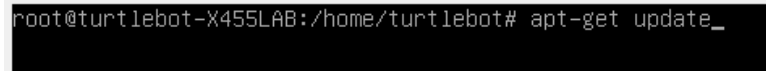

Gambar 19. Update Asterik

b. Setelah proses update selesai, selanjutnya menginstall asterisk pada ubuntu dengat sintax apt-get install asterisk, seperti yang terlihat pada Gambar 20.

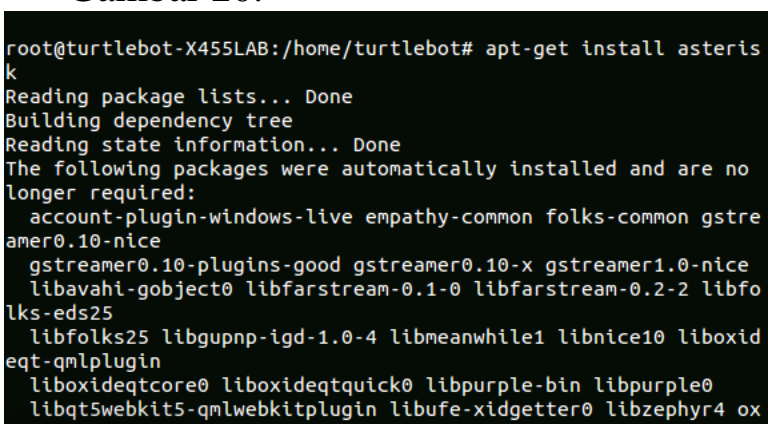

Gambar 20. Instalasi Asterik

c. Setelah selesai menginstal asterisk, langkah selanjutnya yaitu mengkonfigurasi sip.conf pada asterisk. sip.conf ini berfungsi untuk membuat atau menambahkan user yang akan didaftarkan pada asterisk. Seperti yang terlihat pada Gambar 21.

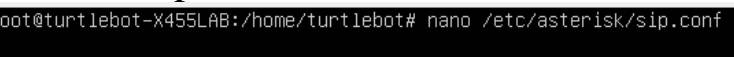

Gambar 21. Konfigurasi File Default

d. Kemudian membuat account user dibagian paling bawah sip.conf, seperti yang terlihat pada Gambar 22 .

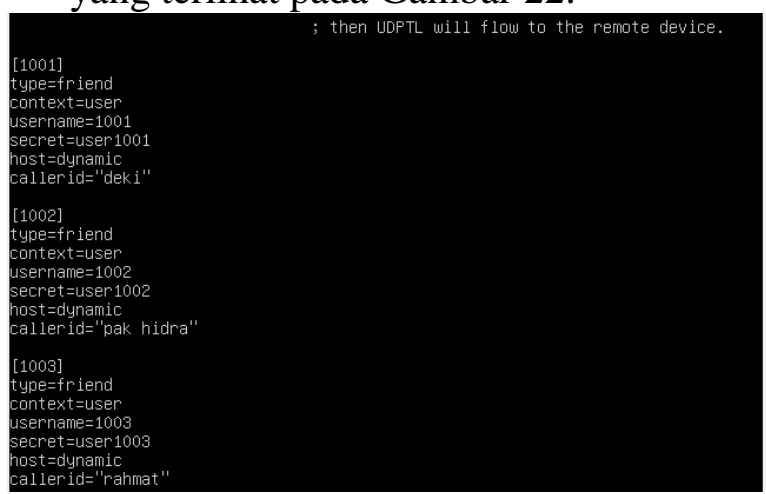

Gambar 22. Membuat Account

e. Selanjutnya membuat extensions pada asterisk, seperti yang terlihat pada Gambar 23.
Gambar 23. Membuat Extensions

f. Selanjutnya membuat script extentions dibagian paling bawah pada extensions.conf. Extensions digunakan untuk user bisa memanggil atau menelepon ulang user lain. seperti yang terlihat pada Gambar 24.

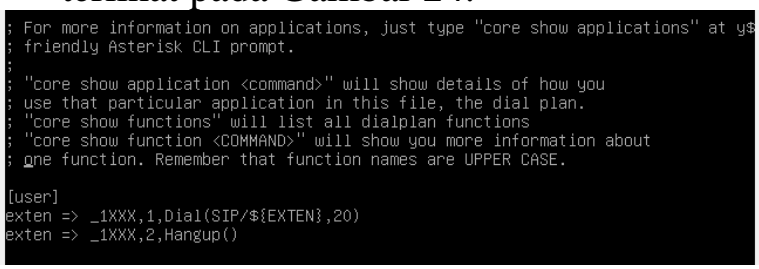

Gambar 24. Script Extentions

g. Kemudian Membuat alamat ip address supaya bisa diakses diklien, dengan sintax nano letc/network/interfaces seperti yang terlihat pada Gambar 25 .

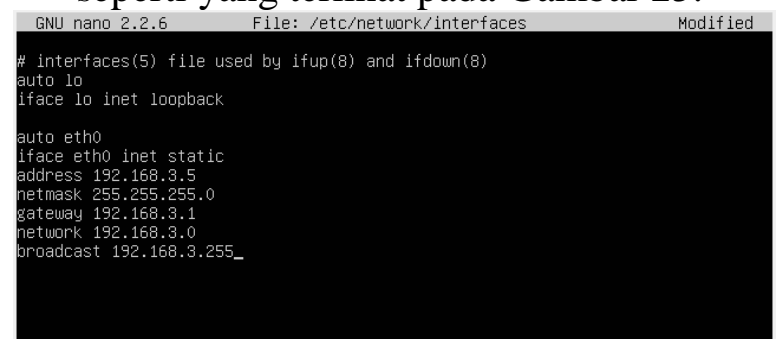

Gambar 25. IP Address

Setelah melakukan instalasi Asterik, selanjutnya melakukan instasi Sentora dengan langkah-langkah sebagai berikut :

a. Menginstal sentora dengan sintax bash $<$ curl $-L$ $-S s$ http://sentora.org/install), Seperti yang terlihat pada Gambar 26.

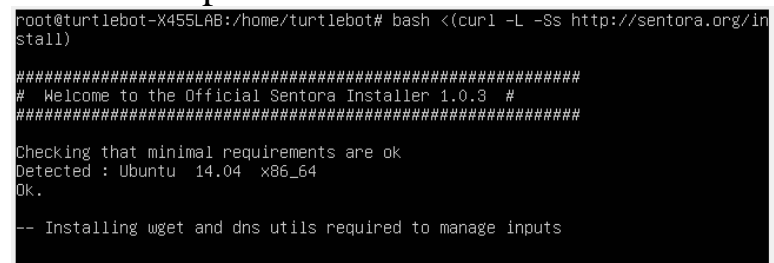

Gambar 26. Instalasi Sentora

b. Kemudian melalakukan pemilihan wilayah geografis tempat berada sekarang dan Memilih kota atau daerah waktu yang sesuai dengan daerah waktu 
Indonesia. Selanjutnya membuat subdomain dan ip address pada sentora panel. Ip address yang didapatkan saat menginstal sentora yaitu 103.252.189.10, seperti yang terlihat pada Gambar 27.

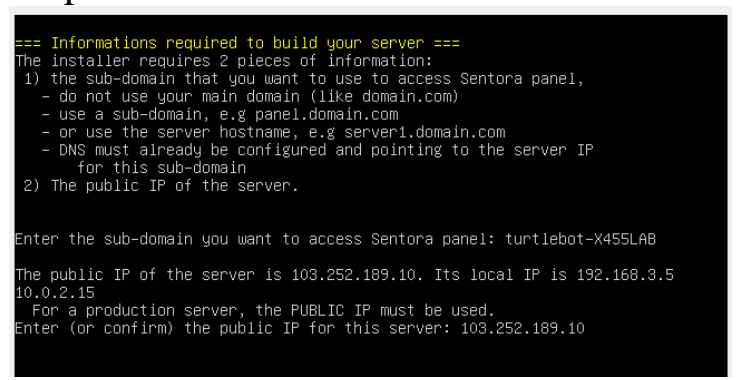

Gambar 27. Membuat Sub-domain dan IP Address

c. Untuk melanjutkan penginstalan sentora dipilih accept and install (y), seperti yang terlihat pada Gambar 28.

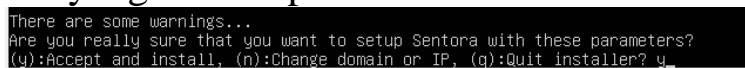

Gambar 28. Accept and Install

d. Proses selanjutnya yaitu menginstall web server dan software lain yang berhubungan dengan sentora, seperti apache, mysql, php, phpmyadmin dan software pendukung lainnya.

Selanjutnya, membuat account VoIP pada aplikasi 3CX Phone dan diikuti dengan membuat account VoIP di aplikasi zoiper. Setelah itu, melakukan pengubahan Ethernet Card disaat server portable yang dihubungkan tidak support dengan PC yang lain dengan langkah sebagai berikut :

a. Tampilan pada saat server portable yang dihubungkan ke PC lain, seperti yang pada Gambar 29.

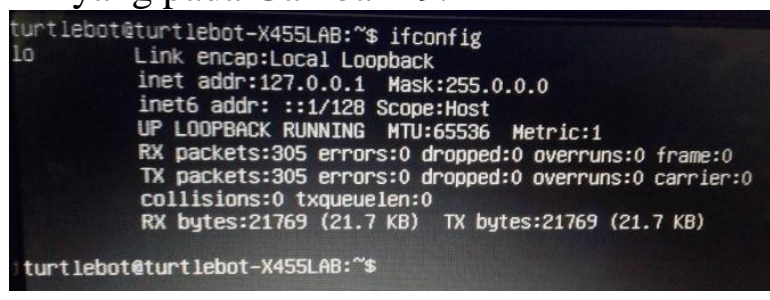

Gambar 29. Tidak Ada Ethernet Card b. Berikut tampilan ethernet card sebelum diubah, seperti yang terlihat pada Gambar 30.

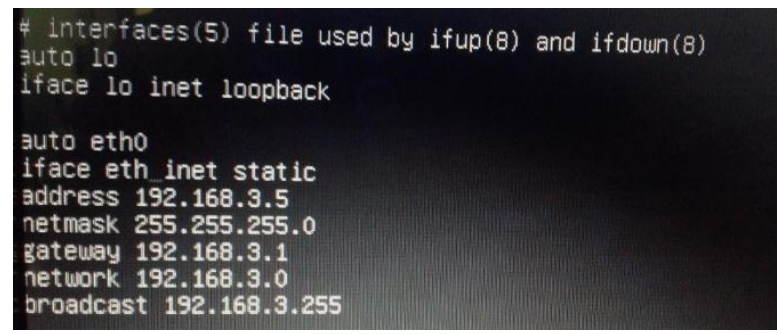

Gambar 30. Tampilan Ethernet card sebelum diubah

c. Selanjutnya mengubah ethernet card dengan sintax nano letc/netword/interfaces, seperti yang terlihat pada Gambar 31.

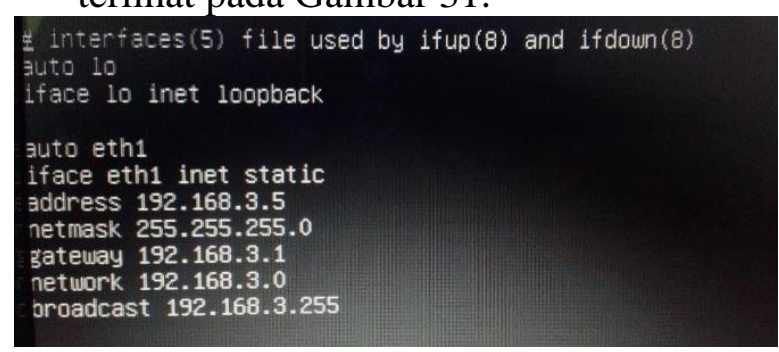

Gambar 31. Tampilan Mengubah Ethernet Card

d. Tampilan ethernet card yang sudah diubah, seperti yang terlihat pada Gambar 32.

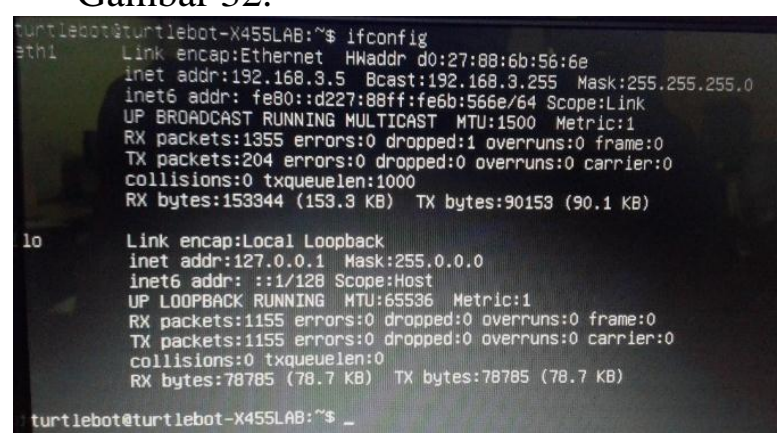

Gambar 32. Ethernet card sudah Support

Setelah server portable untuk VoIP dan web server selesai dibuat, maka selanjutnya adalah melakukan pengujian terhadap server portable yang telah dibuat. Langkah-langkah dalam melakukan pengujian tersebut diantaranya sebagai berikut: 
Sebelum masuk ke booting bios terlebih dahulu harus menghubungkan flashdisk pada PC. Seperti yang terlihat pada Gambar 33.

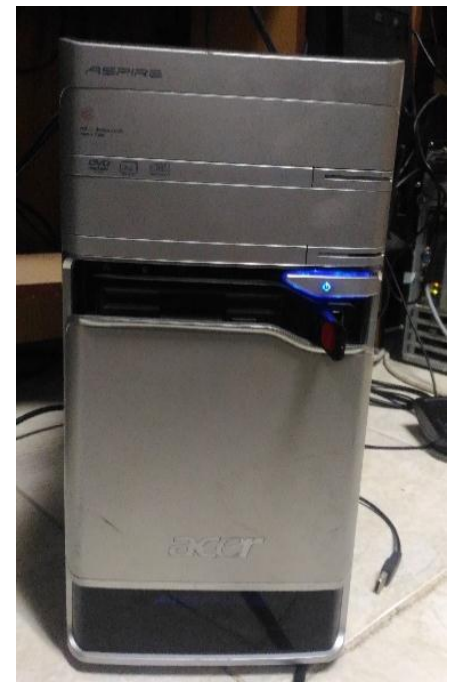

Gambar 33. Menghubungkan Flashdisk

Untuk bisa menjalankan server portable pada flashdisk harus mengatur booting bios dengan menekan tombol delete, seperti yang terlihat pada Gambar 34.

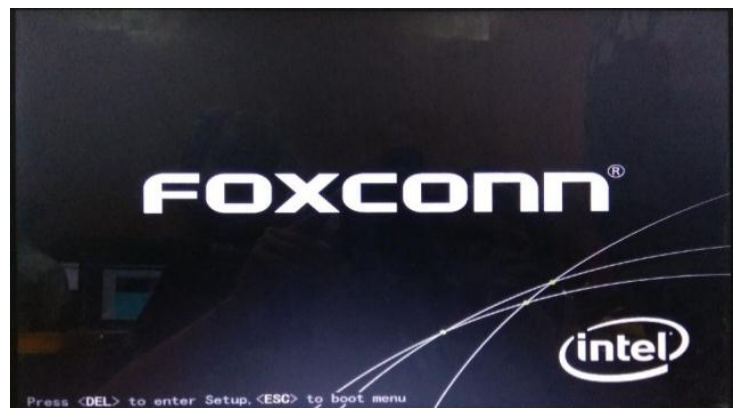

Gambar 34. Menekan Tombol DEL

Tahapan selanjutnya menjadikan flashdisk menjadi boot pertama, supaya server portable bisa dijalankan. seperti yang terlihat pada Gambar 35.

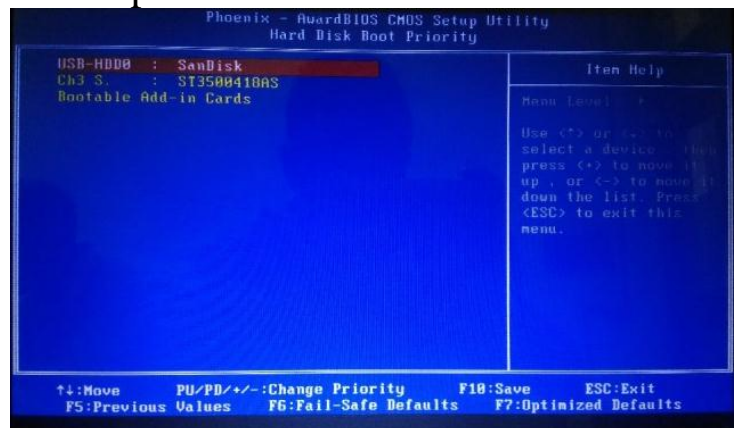

Gambar 35. Boot pertama
Pada tahapan melakukan pengujian VoIP menggunakan aplikasi 3CX Phone dan Zoiper adalah sebagai berikut.

a. Laptop dengan laptop

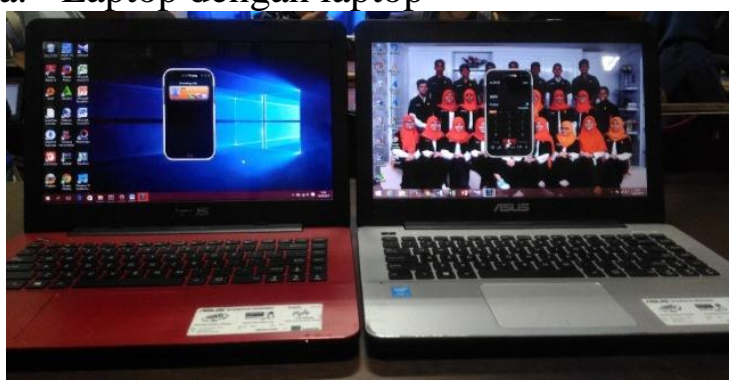

Gambar 36. Laptop dengan Laptop

Pada Gambar 36. aplikasi yang digunakan pada laptop yaitu aplikasi 3CX Phone. laptop yang berada disebelah kanan menelepon atau memanggil laptop yang yang berada sebelah kiri dengan nomor id yang sudah didaftarkan pada aplikasi 3CX Phone.

b. Laptop dengan Handphone

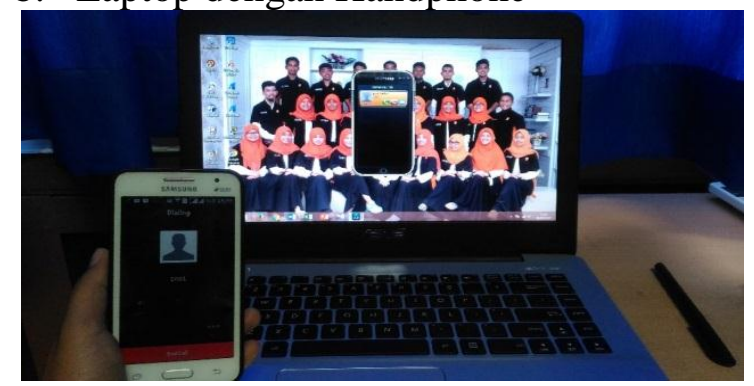

Gambar 37. Laptop dengan Handphone

Pada Gambar 37 aplikasi yang digunakan pada handphone yaitu aplikasi Zoiper, handphone menelepon atau memanggil laptop dengan nomor id yang sudah didaftarkan pada aplikasi 3CX Phone.

c. Handphone dengan Handphone

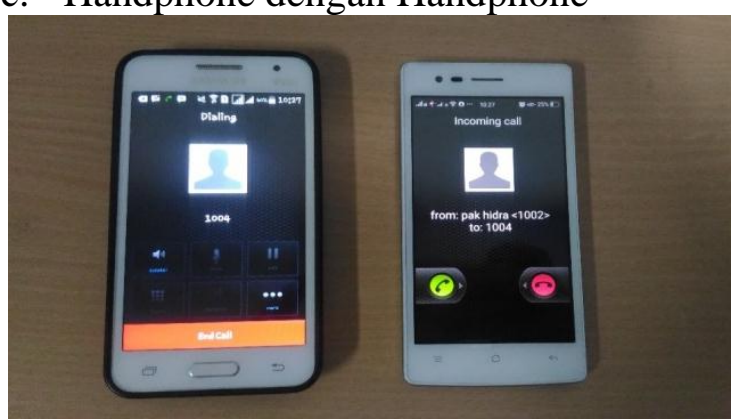

Gambar 38. Handphone dengan Handphone 
Pada Gambar 38 handphone yang berada disebelah kiri menelepon atau memanggil handphone yang berada disebelah kanan dengan nomor id yang sudah didaftarkan pada aplikasi zoiper.

Tabel 1. Pengujian VoIP

\begin{tabular}{|l|l|l|l|}
\hline No & Jarak & \multicolumn{1}{|c|}{ Hasil } & Kualitas \\
\hline 1 & $\begin{array}{l}1-10 \\
\text { Meter }\end{array}$ & Terhubung & Suara jelas \\
\hline 2 & $\begin{array}{l}11-15 \\
\text { Meter }\end{array}$ & Terhubung & $\begin{array}{l}\text { Delay, } \\
\text { Suara } \\
\text { masih } \\
\text { Jelas }\end{array}$ \\
\hline 3 & $\begin{array}{l}16-22 \\
\text { meter }\end{array}$ & Terhubung & $\begin{array}{l}\text { Delay, } \\
\text { Suara } \\
\text { Kurang } \\
\text { Jelas }\end{array}$ \\
\hline 4 & $23>$ & Terputus & $\begin{array}{l}\text { Tidak ada } \\
\text { suara }\end{array}$ \\
\hline
\end{tabular}

Pada Tabel 1 jarak yang dicapai tidak terlalu jauh karena menggunakan TP Link. Jika jarak 1-10 meter suaranya jelas, tetapi jika jaraknya 11-15 meter akan terjadi delay meski suara masih jelas. Jika melebih dari 16 meter akan terjadi delay, suara pun jadi kurang jelas dan jaringan bisa terputus jika melebihi dari 23 meter.

\section{Pengujian Web Sever}

Tampilan web yang sudah di-hosting dengan menggunakan sentora panel, seperti yang terlihat pada Gambar 39.

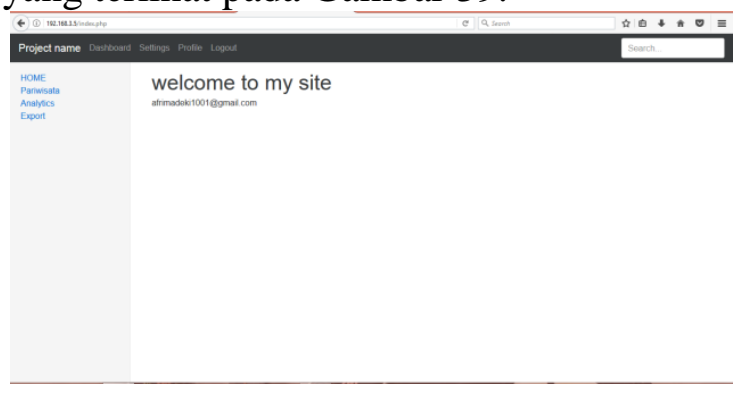

Gambar 39. Tampilan Web
Tampilan web setelah membuka menu pariwisata pada web, seperti yang terlihat pada Gambar 40.

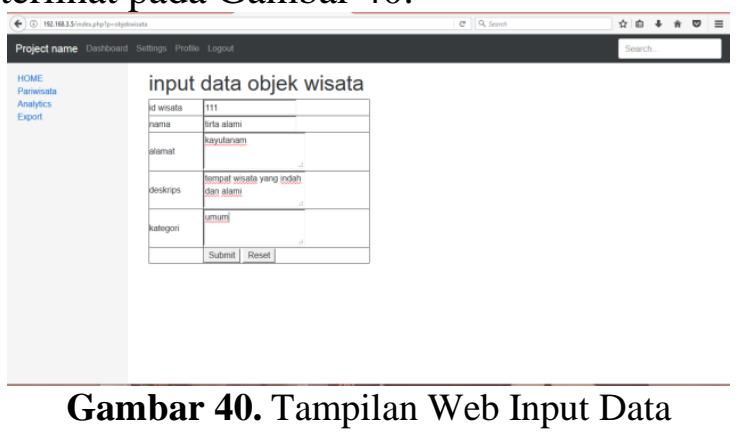

Tampilan web setelah meng-input data, seperti yang terlihat pada Gambar 41.

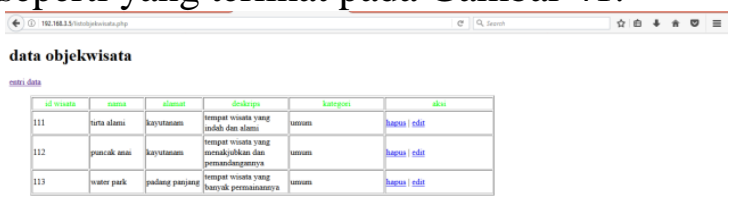

Gambar 41. Setelah Input Data

Tampilan database setelah meng-input data di-web, seperti yang terlihat pada Gambar 42 .

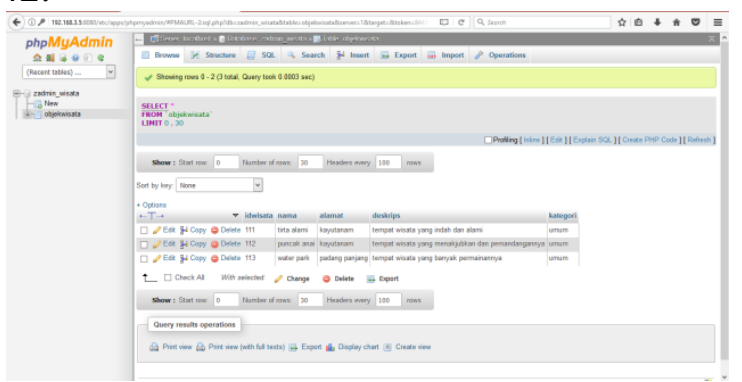

Gambar 42. Tampilan Database yang sudah di-Input

\section{SIMPULAN}

Dari pembahasan diatas, dapat diperoleh simpulan sebagai berikut :

1. Server portable bisa dibawa kemana saja dan bisa digunakan di PC atau laptop untuk mempermudahkan kerja seorang administrator, dengan menggunakan port USB.

2. Menginstal sistem operasi ubuntu menggunakan aplikasi Universal USB Installer supaya bisa diinstal diflashdisk.

3. Membangun server VoIP menggunakan asterisk, dengan memanfaatkan aplikasi 
3CX Phone dan zoiper untuk menelpon atau menghubungi user yang lain.

4. Membangun web server dengan sentora panel, keunggulan sentora panel yaitu memiliki packet seperti apache, php, mysql, phpmyadmin dan software pendukung lainnya sudah terinstal, sehingga tidak perlu diinstal satu persatu.

5. Server portable tidak perlu diinstal ulang jika mengalami kerusakan karena karena menggunakan aplikasi usb image tool untuk mem-backup dan merestore.

6. Kecepatan kinerja server portable sama dengan server yang sudah diinstal di PC baik itu server VoIP maupun web server.

\section{SARAN}

Saran untuk penelitian selanjutnya antara lain :

1. Diharapkan untuk ke depannya bila ingin mengembangkan server portable ini, hendaknya menggunakan flashdisk yang berkapitas besar, agar bisa menginstal software yang banyak.

2. Diharapkan untuk kedepannya server portable bisa dikembangkan dengan menginstal software yang bermanfaat bagi pengguna, seperti mail server dan lainnya.

3. Diharapkan bisa menginstal file manager pada sentora panel, sehingga tidak perlu lagi meng-input web menggunkan filezilla.

4. Diharapkan menggunakan TP Link yang memiliki jangkauan yang luas, supaya VoIP bisa digunakan meski jangkauannya cukup jauh.

5. Diharapkan kedepannya menggunakan ip public supaya bisa mengakses VoIP dan web server meskipun berada di luar kota maupun luar provinsi.

\section{DAFTAR PUSTAKA}

[1] K. N. P. Riyanto dan R. , "Membangun Webserver Intranet Dengan Linux,"
Jurnal Media Informatika, vol. 9, pp. 35, 2013.

[2] D. F. J. Patih, H. Fitriawan dan Y. Yuniati, "Analisa Perancangan Server Voip (Voice Internet Protocol) Dengan Opensource Asterisk Dan Vpn (Virtual Private Network) Sebagai Pengaman Jaringan Antar Client," jurnal Informatika dan Teknik Elektro Terapan, vol. 1, p. 43, 2012.

[3] WAHANA KOMPUTER, Administrasi Jaringan dengan Linux Ubuntu 11, Semarang Andi, 2011.

[4] I. Sofana, Mudah Belajar Linux, Bandung: Informatika, 2010.

[5] Y. Arta, "Implementasi Voice over Internet Protocol (VOIP) pada Biro Administrasi Informatika Teknologi Universitas Islam Riau," Jurnal SAINS, vol. 4, pp. 564-565, 2015.

[6] [Online].Available:

http://www.sentora.org/about [Diakses 8 September 2017].

[7] "Fungsi Dan Pengertian Web Server Berserta Contoh," [Online]. Available: http://berita.sugawebsite.com/fungsipengertian-web-server-dan-contoh/. [Diakses 13 Juni 2017]

[8] D. Abdullah, "PERANCANGAN DAN IMPLEMENTASI VIRTUAL HOSTING MENGGUNAKAN LINUX," Jurnal Penelitian Teknik Informatika Universitas Malikussaleh,Lhokseumawe-Aceh, p. 11.

[9] K. N. P. Riyanto dan R. , "Membangun Webserver Intranet Dengan Linux," Jurnal Media Informasi, vol. 9, pp.35,2013 